\title{
Towards a science of eating disorders: Replacing myths with realities: The fourth Birgit Olsson lecture
}

\author{
Cynthia M. Bulik ${ }^{1,2,3}$ \\ ${ }^{1}$ Department of Psychiatry and ${ }^{2}$ Department of Nutrition, University of North Carolina at Chapel Hill, Chapel Hill, NC, USA, and \\ ${ }^{3}$ Department of Medical Epidemiology and Biostatistics, Karolinska Institutet, Stockholm, Sweden
}

\begin{abstract}
Background: For too long we have been "stuck" in old perspectives that have hampered the advance of knowledge. In part, this is related to the challenges that people have in unlearning misinformation. Aim: To address the need for an upgrade in the eating disorders field. Method: To assist with replacing outdated and inaccurate ideas with new data, this lecture reviewed novel approaches to eating disorders that engage scientists and clinicians from diverse fields to approach questions about aetiology and treatment of eating disorders through new lenses. This forwardlooking lecture outlined critical questions that need to be addressed to move the field forward and strategies for engaging scientists from different fields. Results: Leading-edge findings on genetics, intestinal microbiota, and neuroscience are reviewed. Conclusions: This review encourages the integration of new evidence-based knowledge to form the backbone of our understanding of and approach to eating disorders.
\end{abstract}

\author{
ABSTRACT \\ Anorexia nervosa, binge \\ eating disorder, bulimia \\ nervosa, genetics, \\ microbiota, neurobiology
}

\section{The challenge of unlearning}

The science of eating disorders has been hampered by decades of misunderstanding and misconceptions about the illnesses. Both lay and academic opinions have perpetuated myths about the aetiology of eating disorders, their treatment, and prospects for recovery. As educators, it is critical that we move away from teaching outdated information about eating disorders. Emerging clinicians and researchers deserve fresh, evidence-based knowledge so that they can approach individuals with eating disorders and their families unburdened by erroneous information that can hinder detection and engagement in treatment. Since repeating erroneous myths only serves to solidify the associations in people's minds, this lecture focused on a path forward for introducing novel scientific findings that engage researchers from a wide variety of disciplines in order to advance the field.

Unlearning is challenging for humans. False beliefs, once learned, become sticky and are resistant to extinction. One of the most damaging examples in recent medicine is the fallacious association between vaccines and autism (1), which even after having been retracted from the scientific literature and deemed fraudulent (2), has continued to garner significant momentum from parents and public figures (3-5), resulting in outbreaks of diseases that had been eradicated by universal vaccine policies $(6,7)$. We face a similar stickiness in the eating disorders field and require broad, data driven, and coordinated approaches to change public and medical opinion.

\section{Introducing new knowledge by addressing critical questions}

One way to begin to change opinion is to determine what the critical questions in the field are that need to be addressed through new science. These can be new questions or old questions that have been overlooked or evolved into untested assumptions about eating disorders. Four basic critical questions were addressed in this lecture: aetiological continuum, risk prediction, tipping point, and the fourth dimension: time.

\section{Aetiological continuum}

For decades we have assumed that the behaviours and thought processes that we call "disordered eating" such as dieting, overeating, body dissatisfaction, and drive for thinness lie on an aetiological continuum with the diagnosable eating disorders such as anorexia nervosa ( $\mathrm{AN})$, bulimia nervosa (BN), and binge eating 
disorder (BED). In research on all three disorders, researchers commonly broaden inclusion criteria in their study populations in order to boost statistical power (8). In some instances, the broadening is mild and only extends to subthreshold conditions (9-11). In other instances the relative rarity of threshold and subthreshold cases forces researchers to study these phenotypically similar phenomena such as body dissatisfaction which may or may not be aetiologically related to AN, $\mathrm{BN}$, or BED. Much of what we know in the field comes from samples defined by these presumably related phenomena. If in fact we find, for example through genetic studies, that individuals who harbour these traits, but do not have threshold eating disorders are aetiologically distinct, we will have to revisit the conclusions that we have drawn in the field based on samples defined in that way. This does not mean that these phenomena are unimportant to study; it will simply mean that they do not represent continuous traits that at the extreme ends of the distribution define eating disorders. Rather, traits such as body dissatisfaction may exist in the population from mild to severe and traits such as AN may exist in the population from mild to severe, but the two continua may be aetiologically distinct but linked by superficial phenotypic similarity.

\section{Risk prediction}

Imagine a scenario in which a group of 12-year old girls and a boys' wrestling team decided to go on a diet on a Monday. The girls did so ostensibly because their teacher was dieting and encouraged healthful eating and weight control in her class; the boys did so to be able to wrestle in a lower weight class. What happened after the initiation of the diet in these children is functionally a biological and psychological black box. Discovering what occurs in that black box both biologically and psychologically is a critical question to be answered.

By Friday, the majority of the dieting kids were fed up with the diet. Most of the class went out for pizza and ice cream and gave up the quest for energy restriction. For a small percentage, that fairly brief exposure to negative energy balance (i.e. less energy expended than consumed) tripped a switch and unleashed an urge to transgress their satiety boundary and compensate for the under-consumption of energy throughout the week. Breaking the diet and overeating became the first step in loss of control eating and repeat dieting could make the satiety boundary become increasingly pale and ignorable. For a very small percentage of the girls and boys, the diet brought an unpredictable sense of calm. Those kids might have been the ones who were particularly anxious and irritable at baseline, whose biology had a paradoxical reaction to food deprivation. For them, rather than increasing their irritability and discomfort, negative energy balance relieved them of their inner dysphoria. For them, starvation was reinforcing, and the black box represented their unusual response to starvation and the lure that drew them into the path of AN. The question for the field to answer is, "what are the mechanisms in the black box that lead each of those groups of children to respond to negative energy balance in the way that they do?"

\section{Tipping point}

A third critical question is, "What is the tipping point for developing $\mathrm{AN}, \mathrm{BN}$, and BED?" As we have heard frequently, many individuals go on a weight loss diet, but only a small percentage of them ever develop AN. Likewise, episodes of overeating are nearly ubiquitous in the developed world, but only a small percentage of individuals go beyond overeating to the point of binge eating and feeling out of control. Our science must address what the critical factors are that characterize these tipping points. Factors such as genetics, stress reactivity, emotion dysregulation, infection, hormones, the gut microbiota, gut peptides, and co-morbid psychopathology may all play a role in defining the tipping point into pathology.

\section{The fourth dimension}

As a field, we have neglected time. Our studies of risk factors have commonly viewed all time points before the onset of illness monotonically. Although methodologically challenging, it is essential that we infuse our risk factor research with a developmental perspective. That which acts as a risk factor at age 12 may not be a risk factor at age 6 or 18. Failing to allow for developmental heterogeneity can lead to overlooking significant findings and lead to false conclusions. A valuable example is the now classic twin studies by Klump et al. $(12,13)$ who identified genetic factors that contributed to variance in liability to eating disorders after, but not before puberty. Had they only studied their pre-pubertal twins, we might have overlooked the role of genetics in eating disorders aetiology.

\section{How to address these critical questions}

\section{Reducing isolationism}

The eating disorders field has been an island. We are a small field and we have not been gregarious in engaging 
external scientists in our work. We need an infusion of new ideas and new scientists in order to bring the field into the 21st century.

\section{What makes eating disorders intriguing?}

Part of the way we entice others into studying eating disorders is to educate them about the intriguing facets of eating disorders. The eating disorder phenotypes are intriguing as the represent fundamental dysregulation of behaviours that are essential for life. Being complicit in attributing their cause to will power, stubbornness, and vanity has repelled scientists who may be interested in more fundamental and life-essential questions. The bottom line is that treatment outcome is unacceptably poor, especially for AN. We have no effective medications for AN, and only one medication for BN (fluoxetine) and one for BED (lisdexamphetamine), that have been approved by the United States Food and Drug Administration, neither of which offers long-term cure. The discovery of new biology may yield new "druggable targets" for each of these disorders, and understanding their biology has widespread understanding not just for the eating disorders, but also for co-morbid psychiatric conditions and appetite, weight, and metabolic dysregulation.

\section{Anorexia nervosa}

AN is intriguing to those outside of our field because of the paradoxical reaction to starvation. For individuals prone to AN, starvation is reinforcing, anxiolytic, and even euphorigenic $(14,15)$. Activity is more reinforcing than food $(16,17)$. Satiety is unpleasant $(18)$. Fats are aversive $(19,20)$. Clinical experience verifies that refeeding is agony and feels terrible. Finally, acutely ill individuals with AN do not exhibit classic sickness behaviours characteristic of the presence of inflammatory processes $(21,22)$. Each of these is in stark contrast to the majority of individuals in the world who regularly battle with the opposite tendencies in their quest for weight loss.

\section{Bulimia nervosa}

BN is intriguing, as self-induced vomiting is highly heritable ( 70\%) (23). Why this should be the case is not entirely clear. It is a reliably measured phenotype, which could contribute to the high heritability estimate; however, it is conserved across species (birds do it; wolves do it), and the ability to self-induce vomiting varies across the human population. Most individuals despise vomiting, yet individuals with $\mathrm{BN}$ report it to be both negatively reinforcing (i.e. removes the adverse consequences of a binge) and positively reinforcing (i.e. euphorigenic) $(24,25)$. We have not yet succeeded in developing animal models of self-induced vomiting, as many of our favourite lab animals (i.e. rats) are non-emetic.

\section{Binge eating disorder}

BED has attracted considerable press since making its way into the DSM-5 and it too holds intrigue for scientists outside of the eating disorders field. Humans have variable appetite responses to stress. We all know people who eat more when stressed, do not eat at all when stressed, or whose appetites seem unphased by stress (26). Why this is the case remains unknown. Some people find that negative emotions trigger binge episodes and to most people this is intuitive, but for others positive emotions can set them off (27). Both impulse dyscontrol (28) and aberrant reward responses have been implicated in BED (29), but we do not know how and whether these systems interact. Finally, the circadian dysregulation in BED is apparent to clinicians $(30,31)$. People with the disorder tend not to eat breakfast and say their stomachs only wake up after noon. Binge eating is often confined to the afternoon and evening hours and BED and night eating syndrome share some genetic factors (32). That an out of sync biological clock may contribute to BED is an intriguing hypothesis worthy of exploration.

Together these idiosyncratic characteristics render eating disorders truly fascinating phenotypes and ones to which scientists from a range of disciplines could meaningfully contribute.

\section{Genetics}

\section{Where have we been?}

The genetics of eating disorders got off to a slow start in part due to the fact that few believed that genes played a role. We no longer have to emphasize that eating disorders run in families and that twin studies have documented considerable heritability for $\mathrm{AN}, \mathrm{BN}$, and BED (33). Telling patients that genes are involved now flows freely from clinicians' mouths when discussing the ubiquitous question of, "Why me?" even though we have not yet identified the specific genes implicated in risk for these disorders.

\section{State of the science}

Like much of psychiatric genetics, we wallowed through the dark years of candidate gene and linkage studies, 
demonstrating considerable hubris in believing that we could choose one from 23,000 genes that might play a role in a complex disorder like AN or BN using minute sample sizes. Millions of dollars later, we had little to show. With the advent of genome-wide association studies (GWAS), the field has burgeoned with promise. Schizophrenia is the poster child for psychiatric genomics and has illustrated remarkably how increasing sample size yields fruit. In their initial GWAS with 3000 cases (34), the schizophrenia consortium identified no significant loci for their disorder. Two years later, reaching a sample size of 9000 , five new significant loci were announced showing that sample size matters in psychiatric genomics (35). Subsequent publications raised the ante: 14,000 cases yielded 22 loci (36); and now with 34,000 cases, this group has identified 108 loci for schizophrenia which represent a rich search space for drilling down into the biology of these genes to understand how they influence risk for schizophrenia (37).

Two GWAS of AN have been published, and both represent efforts similar to the initial schizophrenia foray into GWAS. Both Wang et al. (1033 cases) (38) and Boraska et al. (2907 cases) (39) failed to identify significant hits. However, sign tests in the Boraska study strongly suggest that increasing sample size will lead to a similar discovery trajectory as that witnessed in schizophrenia. Indeed serious global efforts are currently underway to massively increase sample size for AN, and $\mathrm{BN}$ and BED will follow.

Success in this area has the potential to revolutionize our understanding of risk, prevention, and treatment of eating disorders.

\section{Intestinal microbiota}

Knowledge on the role that the gut microbiota plays in obesity, is a natural lead in to the possibility that intestinal bugs could play a role in AN (40). This novel approach has its sceptics; however, recall the revolutionary Helicobacter pylori story which also attracted doubters $(41,42)$. The discovery that peptic ulcers were not just caused by stress, but by a bacterium, changed the world, and enabled individuals with ulcers to experience cure rather than long-term partial symptom management, prolonged pain, and quality of life decrements. Although it is unlikely that we will discover a similar paradigm-altering bug in $\mathrm{AN}$, exploring the role of the intestinal microbiota as an adaptation to prolonged starvation may indeed lead us to adjunct treatments that make refeeding less distressing and uncomfortable to patients and equalize fat distribution during weight restoration.
Mounting evidence suggests that the intestinal microbiota regulate key features of $\mathrm{AN}$, including weight regulation, energy metabolism (43), anxiety, and depression (44), providing a strong rationale for exploring the role of gut microbes in AN. Yet there has been limited research to date, none of which has explored the functional role of the intestinal microbiota in the maintenance of and recovery from AN (45-48). The existing literature on the gut-brain axis evokes a model in which changes in gut microbial communities associated with extreme weight loss may perpetuate and contribute to AN via effects on weight and mood, but further research is needed to define and understand the alterations and functional effects of AN intestinal microbiotas on adiposity and behaviour. This research is key to designing microbiota-modulating treatment strategies (e.g. promotion or elimination of specific bacterial taxa), which could improve the psychological and physical treatment experience of patients and would comprise a significant therapeutic advance in treatment of AN.

\section{Neuroscience}

Advances in the neuroscience of eating and appetite could fill an entire lecture; however, this lecture showcased one series of investigations that together with other parallel endeavours may piece together the complex interconnected and partially redundant networks in the brain that control the central behaviours of feeding.

Jennings and Stuber (49-51) have focused on an area of the brain called the bed nucleus of the stria terminalis or the BNST. The BNST GABA neurons have a cell body and a long strand with branched synapses that transmit electrical signals from the BNST into the lateral hypothalamus. Stuber and his team stimulated those synapses' optogenetics. They used genetically engineered proteins from algae that are sensitive to light and genetically engineered viruses to deliver them into the brains of mice. Those proteins then get expressed only in the BNST cells, including in the synapses that connect to the hypothalamus. They then implant fibre-optic cables in the brains of these specially bred mice, and shine light through the cables and onto BNST synapses. A video of this experiment shows what happens when light hit the BNST of mice who had been well fed and under normal conditions would have been indifferent to the presence of food. As soon as the light hit BNST synapses, the mice began to eat the high fat food voraciously even though sated. As soon as the light was turned off, the eating stopped. Repeat times four. This powerful illustration is just a glimpse into the rich work being done on this 
Table 1. Nine truths about eating disorders.*

Truth 1 Many people with eating disorders look healthy, yet may be extremely ill

Truth 2 Families are not to blame, and can be the patients' and providers' best allies in treatment

Truth 3 An eating disorder diagnosis is a health crisis that disrupts personal and family functioning

Truth 4 Eating disorders are not choices, but serious biologically influenced illnesses

Truth 5 Eating disorders affect people of all genders, ages, races, ethnicities, body shapes and weights, sexual orientations, and socioeconomic statuses

Truth 6 Eating disorders carry an increased risk for both suicide and medical complications

Truth 7 Genes and environment play important roles in the development of eating disorders

Truth $8 \quad$ Genes alone do not predict who will develop eating disorders

Truth 9 Full recovery from an eating disorder is possible. Early detection and intervention are important

*Produced in collaboration with the Academy for Eating Disorders "Nine Truths" is based on Bulik's 2014 "Nine eating disorders myths busted" talk at the US National Institute of Mental Health (52). Leading associations in the field of eating disorders also contributed their valuable input.

pathway, and together with similar research on other brain networks, will start to piece together the complexities not only of normal feeding behaviour but also of the aberrant processes that characterize eating disorder such as eating in the absence of hunger and not eating in the presence of starvation.

\section{Conclusion and realities}

Recently, the international Academy for Eating Disorders along with several advocacy organizations crafted "nine truths" (52) about eating disorders to guide stakeholders toward a more contemporary understanding of the realities of the illnesses. Table 1 presents these truths, which have now been translated into several languages. The goal is for these truths to form the foundation for contemporary thinking about eating disorders.

A valuable way forward is to engage a broad array of scientists and clinicians to think about eating disorders in new ways and to create previously unimaginable synergies that will lead to new discoveries in the field. AN remains the most lethal of all psychiatric disorders. Suicide is significantly elevated in individuals with AN, $B N$, and BED. Quality of life is seriously impaired and subsequent generations suffer. New methods coupled with open minds present the opportunity of enhanced understanding, prevention, and treatment of these pernicious illnesses.

\section{Disclosure of interest}

The author is grant recipient from Shire.

\section{References}

1. Wakefield AJ, Murch SH, Anthony A, Linnell J, Casson DM, Malik $M$, et al. Ileal-lymphoid-nodular hyperplasia, nonspecific colitis, and pervasive developmental disorder in children. Lancet 1998;351:637-41.

2. Retraction - lleal-lymphoid-nodular hyperplasia, non-specific colitis, and pervasive developmental disorder in children. Lancet 2010;375:445.

3. Greenfield K. The autism debate: Who's afraid of Jenny McCarthy? Time, 25 February 2010.
4. Kirby D. The autism-vaccine debate: Why it won't go away. Huffington Post, 11 February 2011. Available from http:// www.huffingtonpost.com/david-kirby/autism-vaccine-_b_ 817879.html

5. McCarthy J. In the vaccine-autism debate, what can parents believe?: Huffington Post 25 May 2011. Available from http://www.huffingtonpost.com/jenny-mccarthy/ vaccine-autism-debate_b_806857.html

6. Rise in measles cases marks a "wake-up call" for U.S. NPR National Public Radio, 29 January 2015. Available from http://www.npr.org/blogs/health/2015/01/29/382436262/ rise-in-measles-cases-marks-a-wake-up-call-for-u-s

7. Facts about the measles outbreak. New York Times, 2 February 2015. Available from http://www.nytimes.com/ interactive/2015/02/02/us/measles-facts.html?_r=1

8. Dellava JE, Thornton LM, Lichtenstein P, Pedersen NL, Bulik CM. Impact of broadening definitions of anorexia nervosa on sample characteristics. J Psychiatr Res 2011;45:691-8.

9. Klump $\mathrm{KL}$, Miller KB, Keel PK, McGue M, lacono WG. Genetic and environmental influences on anorexia nervosa syndromes in a population-based twin sample. Psychol Med 2001;31:737-40.

10. Raevuori A, Kaprio J, Hoek HW, Sihvola E, Rissanen A, Keski-Rahkonen A. Anorexia and bulimia nervosa in samesex and opposite-sex twins: Lack of association with twin type in a nationwide study of Finnish twins. Am J Psychiatry 2008;165:1604-10.

11. Wade TD, Bergin JL, Tiggemann M, Bulik CM, Fairburn CG. Prevalence and long-term course of lifetime eating disorders in an adult Australian twin cohort. Aust N Z J Psychiatry 2006;40:121-8.

12. Klump KL, Culbert KM, Slane JD, Burt SA, Sisk CL, Nigg JT. The effects of puberty on genetic risk for disordered eating: Evidence for a sex difference. Psychol Med 2012;42:627-37.

13. Klump KL, Perkins PS, Alexandra Burt $S$, McGue $M$, lacono WG. Puberty moderates genetic influences on disordered eating. Psychol Med 2007;37:627-34.

14. Kaye W. Neurobiology of anorexia and bulimia nervosa. Physiol Behav 2008;94:121-35.

15. Kaye WH, Wierenga CE, Bailer UF, Simmons AN, BischoffGrethe A. Nothing tastes as good as skinny feels: the neurobiology of anorexia nervosa. Trends Neurosci 2013;36:110-20.

16. Giel KE, Kullmann S, Preissl H, Bischoff SC, Thiel A, Schmidt $U$, et al. Understanding the reward system functioning in anorexia nervosa: Crucial role of physical activity. Biol Psychol 2013;94:575-81. 
17. Klein DA, Schebendach JE, Gershkovich M, Bodell LP, Foltin RW, Walsh BT. Behavioral assessment of the reinforcing effect of exercise in women with anorexia nervosa: Further paradigm development and data. Int J Eat Disord 2010;43:611-18.

18. Holsen LM, Lawson EA, Blum J, Ko E, Makris N, Fazeli PK, et al. Food motivation circuitry hypoactivation related to hedonic and nonhedonic aspects of hunger and satiety in women with active anorexia nervosa and weight-restored women with anorexia nervosa. J Psychiatry Neurosci 2012;37:322-32.

19. Spring VL, Bulik CM. Implicit and explicit affect toward food and weight stimuli in anorexia nervosa. Eat Behav 2014;15:91-4.

20. Simon Y, Bellisle F, Monneuse MO, Samuel-Lajeunesse B, Drewnowski A. Taste responsiveness in anorexia nervosa. Br J Psychiatry 1993;162:244-6.

21. Omodei D, Pucino V, Labruna G, Procaccini C, Galgani M, Perna $F$, et al. Immune-metabolic profiling of anorexic patients reveals an anti-oxidant and anti-inflammatory phenotype. Metabolism: Clin Exper 2015;64:396-405.

22. Pisetsky DS, Trace SE, Brownley KA, Hamer RM, Zucker NL, Roux-Lombard $\mathrm{P}$, et al. The expression of cytokines and chemokines in the blood of patients with severe weight loss from anorexia nervosa: An exploratory study. Cytokine 2014;69:110-15.

23. Bulik CM, Devlin B, Bacanu SA, Thornton L, Klump KL, Fichter MM, et al. Significant linkage on chromosome 10p in families with bulimia nervosa. Am J Hum Genet 2003;72:200-7.

24. Berg KC, Crosby RD, Cao L, Peterson CB, Engel SG, Mitchell $\mathrm{JE}$, et al. Facets of negative affect prior to and following binge-only, purge-only, and binge/purge events in women with bulimia nervosa. J Abnormal Psychol 2013;122:111-18.

25. Smyth JM, Wonderlich SA, Heron KE, Sliwinski MJ, Crosby $\mathrm{RD}$, Mitchell JE, et al. Daily and momentary mood and stress are associated with binge eating and vomiting in bulimia nervosa patients in the natural environment. J Consult Clin Psychol 2007;75:629-38.

26. van Strien T, Ouwens MA, Engel $C$, de Weerth $C$. Hunger, inhibitory control and distress-induced emotional eating. Appetite 2014;79:124-33.

27. Leehr EJ, Krohmer K, Schag K, Dresler T, Zipfel S, Giel KE. Emotion regulation model in binge eating disorder and obesity - a systematic review. Neurosci Biobehav Rev 2015;49C:125-34.

28. Balodis IM, Molina ND, Kober H, Worhunsky PD, White MA, Rajita $S$, et al. Divergent neural substrates of inhibitory control in binge eating disorder relative to other manifestations of obesity. Obesity 2013;21:367-77.

29. Wierenga CE, Ely A, Bischoff-Grethe A, Bailer UF, Simmons $\mathrm{AN}$, Kaye $\mathrm{WH}$. Are extremes of consumption in eating disorders related to an altered balance between reward and inhibition? Front Behav Neurosci 2014;8:410.

30. Harb A, Levandovski R, Oliveira C, Caumo W, Allison KC, Stunkard $A$, et al. Night eating patterns and chronotypes: A correlation with binge eating behaviors. Psychiatry Res 2012;200:489-93.

31. Raymond NC, Neumeyer B, Warren CS, Lee SS, Peterson CB. Energy intake patterns in obese women with binge eating disorder. Obesity Res 2003;11:869-79.
32. Root $T L$, Thornton $L M$, Lindroos $A K$, Stunkard $A J$, Lichtenstein $\mathrm{P}$, Pedersen $\mathrm{NL}$, et al. Shared and unique genetic and environmental influences on binge eating and night eating: A Swedish twin study. Eat Behav 2010;11:92-8.

33. Yilmaz Z, Hardaway A, Bulik C. Genetics and epigenetics of eating disorders. Adv Genom Genet 2015;5:131-50.

34. International Schizophrenia C, Purcell SM, Wray NR, Stone $\mathrm{JL}$, Visscher PM, O'Donovan MC, et al. Common polygenic variation contributes to risk of schizophrenia and bipolar disorder. Nature 2009;460:748-52.

35. Schizophrenia Psychiatric Genome-Wide Association Study C. Genome-wide association study identifies five new schizophrenia loci. Nat Genet 2011;43:969-76.

36. Ripke S, O'Dushlaine C, Chambert K, Moran JL, Kahler AK, Akterin $\mathrm{S}$, et al. Genome-wide association analysis identifies 13 new risk loci for schizophrenia. Nat Genet 2013;45:1150-9.

37. Schizophrenia Working Group of the Psychiatric Genomics C. Biological insights from 108 schizophrenia-associated genetic loci. Nature 2014;511:421-7.

38. Wang K, Zhang H, Bloss CS, Duvvuri V, Kaye W, Schork NJ, et al. A genome-wide association study on common SNPs and rare CNVs in anorexia nervosa. Mol Psychiatry 2011;16:949-59.

39. Boraska V, Franklin CS, Floyd JA, Thornton LM, Huckins LM, Southam $L$, et al. A genome-wide association study of anorexia nervosa. Mol Psychiatry 2014;19:1085-94.

40. Kleiman SC, Carroll IM, Tarantino LM, Bulik CM. Gut feelings: A role for the intestinal microbiota in anorexia nervosa? Int J Eat Disord 2015;48:449-51.

41. Unidentified curved bacilli on gastric epithelium in active chronic gastritis. Lancet 1983;1:1273-5.

42. Marshall BJ, Warren JR. Unidentified curved bacilli in the stomach of patients with gastritis and peptic ulceration. Lancet 1984;1:1311-15.

43. Turnbaugh PJ, Gordon Jl. The core gut microbiome, energy balance and obesity. J Physiol 2009;587:4153-8.

44. Mayer EA, Knight R, Mazmanian SK, Cryan JF, Tillisch K. Gut microbes and the brain: Paradigm shift in neuroscience. J Neurosci 2014;34:15490-6.

45. Armougom F, Henry M, Vialettes B, Raccah D, Raoult D. Monitoring bacterial community of human gut microbiota reveals an increase in Lactobacillus in obese patients and Methanogens in anorexic patients. PLoS One 2009;4:e7125.

46. Pfleiderer A, Lagier JC, Armougom F, Robert C, Vialettes B, Raoult D. Culturomics identified 11 new bacterial species from a single anorexia nervosa stool sample. Eur J Clin Microbiol Infect Dis 2013;32:1471-81.

47. Pickard JM, Maurice CF, Kinnebrew MA, Abt MC, Schenten D, Golovkina TV, et al. Rapid fucosylation of intestinal epithelium sustains host-commensal symbiosis in sickness. Nature 2014;514:638-41.

48. Tennoune N, Chan P, Breton J, Legrand R, Chabane YN, Akkermann K, et al. Bacterial ClpB heat-shock protein, an antigen-mimetic of the anorexigenic peptide alpha-MSH, at the origin of eating disorders. Transl Psychiatry 2014;4:e458.

49. Jennings $J H$, Sparta DR, Stamatakis AM, Ung RL, Pleil KE, Kash $T L$, et al. Distinct extended amygdala circuits for divergent motivational states. Nature 2013;496:224-8. 
50. Sparta DR, Jennings JH, Ung RL, Stuber GD. Optogenetic strategies to investigate neural circuitry engaged by stress. Behav Brain Res 2013;255:19-25.

51. Stamatakis AM, Sparta DR, Jennings JH, McElligott ZA, Decot $H$, Stuber GD. Amygdala and bed nucleus of the stria terminalis circuitry: Implications for addiction-related behaviors. Neuropharmacology 2014;76B:320-8.

52. Academy for Eating Disorders. Press release. AED releases nine truths about eating disorders. Available from http:// www.aedweb.org/index.php/25-press-releases/163-pressrelease-aed-releases-nine-truths-about-eating-disorders 